\title{
EN EL CREPÚSCULO
}

\author{
Eloy RADA \\ UNED
}

Sólo su secretario Eckhart siguió el féretro hasta la tumba. En ella aguardaba el epitafio que el propio Leibniz había escrito: «Huesos de Leibniz».

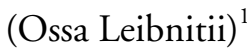

RESUMEN: Entre la abundante correspondencia que Leibniz mantuvo a lo largo de su vida, los investigadores han prestado una especial atención a las cartas que escribió a la Princesa Carolina de Ansbach, principalmente porque estas incluyen la polémica con Samuel Clarke. Nuestro objetivo aquí consiste en esclarecer un aspecto más personal e incluso anecdótico de la figura de Leibniz, en el contexto de los intereses políticos que ocuparon su mente durante los últimos años de su vida.

DesCrIPTOREs: G. W. Leibniz, Princesa Carolina, Samuel Clarke, Teodicea, Abate Conti, Isaac Newton.

ABSTRACT: From among the copious correspondence that Leibniz kept up throughout his life scholars have rightly given attention to the letters he wrote to Princess Caroline of Ansbach, principally because they include the controversy with Samuel Clarke. Our objective here is to throw light upon a more personal and even anecdotal aspect of the figure of Leibniz in the context of the political interests that occupied his mind during the last two years of his life.

KEYwOrDS: Leibniz, Princess Caroline, Samuel Clarke, Teodicea, Isaac Newton, Theodicy, Abate Conti.

${ }^{1}$ Ezequiel de Olaso: G. W. Leibniz. Escritos Filosóficos. «Cronología de Leibniz». Ed.Charcas. Buenos Aires, 1982. pág. 40. 
El viernes 14 de septiembre de 1714 llegaba Leibniz a Hannover de regreso de Viena, tras dos años de ausencia plagados de disculpas, medias verdades, excusas y segundas intenciones. La relación iniciada en 1711 con el Zar Pedro I en Torgau, lleva a Leibniz, y esta vez a petición del Zar y con permiso de su Patrón, a reunirse de nuevo con él en 1712 en los baños de Karlsbad acompanándole hasta Dresde. Como resultado Leibniz se encuentra convertido en lo que jocosamente denominó "Solón de Rusia». Pero al despedirse del Zar no regresa a Hannover, sino que, en secreto, se dirige a Viena a donde llega en Noviembre de 1712, lo que para unos fue una huída hacia delante y para otros una deslealtad imperdonable hacia Su Alteza Electoral Jorge Luis. Llovía sobre mojado, pues su anterior estancia en Viena le había costado una personal reprimenda del Elector quien, de paso, se reservó en exclusiva la potestad de darle permisos de viaje.

A su llegada a Hannover, Leibniz se encontró con que el Elector había partido el Martes anterior hacia Londres para ser proclamado Rey de Inglaterra y había dejado órdenes expresas para él. Tras visitar a la Princesa Carolina en Herrenhausen, su primera carta es para la Emperatriz Amalia el 16 de Septiembre (Klopp.XI, 8-9), en la que lamenta no haber traído consigo cartas de Viena que le hubiesen ayudado ante la corte de Hannover. Y la segunda para el Príncipe Electoral Jorge Augusto (esposo de Carolina) que acompañaba a su padre en la comitiva real camino de Londres. "No me atreví a correr detrás (de la comitiva), pese a que podía decir muchas particularidades agradables...» le dice al Príncipe, y luego entra en su propio problema: "En cuanto a mis intereses particulares he creido que me podia fiar de la bondad y justicia del Rey: aunque me ha sorprendido escuchar de Madame la princesa Real (que me ha conservado sus graciosas bondades que son de una tan grande estima por mi parte junto con las de Vuestra Serenidad Real) que Su Majestad ha dicho de mi: "Él no viene más que cuando yo he llegado a Rey". Espero, por tanto, que lo haya dicho sonriendo".

El 20 de Septiembre escribía al Ministro Bernstorf: «Como he viajado en calidad de anciano no he llegado aqui hasta el viernes pasado, habiendo ya partido el Rey el martes» (K.XI.12) Y, tras algunas opiniones y consejos sobre el reconocimiento al duque de Saboya como Rey de Sicilia, la carta expone las quejas por la situación financiera en que el nuevo Rey le ha dejado como despedida y advertencia final: Suspensión de sueldo. Sin duda Leibniz se dio cuenta de lo grave que era la nueva situación en que se encontraba dentro de la corte de Hannover 
(además sin el apoyo de su querida Sofía) y le hace al Ministro (que por lo demás ya le había advertido en carta del 3 de Marzo - K.XI.6 - sobre el grave riesgo que estaba corriendo) la siguiente consideración final:

«No he querido hacer ninguna gestión que pudiera perjudicar al servicio de un patrono tan grande, al que por tan largo tiempo he servido con afecto y celo. Yo no debía descuidarme por completo de mí mismo, y para dar lugar aquí a una mejor opinión de mí, era preciso hacer ver que todavía se tiene en otros sitios una buena opinión de mí. Pero bien se puede creer que me disgustaría que un trabajo de tantos años resultase inútil» (K-XI.14).

A juzgar por estas afirmaciones Leibniz no estaba muy satisfecho con el grado de estima que recibía del Elector, quien, probablemente sólo veía en él un adorno erudito en su corte. El caso es que, si esta era también la percepción de Leibniz, su viaje a Viena bien podría haber tenido como objetivo, más que hacerse valer ante el Elector, tantear las posibilidades de encontrar un puesto de más alcance, contando con la ayuda que su amigo Antonio Ulrico le podría proporcionar. Es cierto que volvió del viaje como consejero de Justicia del Imperio y del Zar y que estos cargos reflejaban «buena opinión de él en otros sitios». También es cierto que le permitían argumentar como lo hizo. Pero, ¿necesitaba dar lugar (en Hannover) a una mejor opinión? ¿Es que quizá no era todo lo buena que creía merecer? También podríamos imaginar que esta no muy velada queja es de hecho una manifestación elegante, pero explícita, de que otros intereses estaban presentes ahora en su vida, además de los del Elector y nuevo Rey. Por tanto, Berenstorf podría de esta manera saber que Leibniz se estaba haciendo cargo de la «nueva situación» en que estaba dentro de la corte.

Por otra parte, al día siguiente de esta carta a Bernstof escribía al Conde de Bonneval a Viena y decía dos cosas: la primera, "he venido aqui para trabajar durante este invierno en cosas que me podrian desembarazar de ciertas ocupaciones capaces de diferir un poco mi retorno a Viena». La segunda, "Si estoy en estado de obedecer a S.A.R. iré a acompañarla hasta Inglaterra». (K.XI.14-15). Parece que aún no ha asumido plenamente la "nueva situación" y considera que no es tan grave. Y parece también que piensa en retornar a Viena lo antes posible. El 12 de Octubre Carolina y sus hijos (menos el mayor de 17 años) parten hacia Londres sin Leibniz que un mes más tarde escribe a la Princesa (K.XI.19) diciéndole que «su marcha le ha dejado lleno de pena y le ha hecho Hannover insoportable» 
con la gota como acompañante. Y, poco después, en carta a Rèmond de 11 de Febrero de 1715 (G, P. III. 634) le explica que su salud le impidió ir a Londres con la Princesa. Finalmente el día 1 de Diciembre de 1714 (K.XI. pág. 22) el primer ministro Bernstorf le escribe reenviándole correo llegado a Londres para él y le dice con claridad «hacéis bien, Señor, en quedaros en Hannover y retomar ahi vuestros trabajos. No podéis hacer mejor obsequio al Rey, ni reparar mejor las ausencias pasadas que presentando a Su Majestad, cuando regrese a Hannover una buena parte de las obras que espera desde hace ya tanto tiempo" (K.XI.22). Y a comienzos de 1715 (Aiton. 431) «...el rey emitió una orden para Leibniz por la que le prohibia emprender viajes largos hasta que el estudio histórico estuviera completo (Doebner 1881, p. 308)»".

Todos estos datos nos permiten comprender el sentido que podía tener lo que he denominado «nueva situación» $y$, en parte, cómo se había gestado durante su estancia en Viena. La seria advertencia de Bernstof que he mencionado más arriba empieza ahora a ser realidad. Sin embargo, algo muy importante para Leibniz debió retenerle en Viena pese a las advertencias de todos. Si examinamos la correspondencia (y otros escritos) que Leibniz dató en Viena desde finales de 1712 hasta Septiembre de 1714 podemos intuir con cierta aproximación algunos detalles significativos.

Por una parte aparece sin duda un frente político en el cual parece manejar su condición de doble Consejero Imperial y del Zar frente a la potencia casi dominante de Francia. André Robinet ${ }^{3}$ ha estudiado este aspecto con detalle y nos exime de más referencias al legado textual. Me arriesgaré a dar una visión, quizá personal, del fondo del asunto.

Aparentemente, desde su nueva situación de Consejero Imperial, el Imperio le resultaba un punto de vista central en su diseño de relaciones entre estados y confesiones, con extensión hasta Rusia y la lejana China. Resulta significativo el número y variedad de personas con quienes contacta en busca de información, ya sean diplomáticos, viajeros, misioneros o ministros. Los motivos son a veces de

\footnotetext{
${ }^{2}$ E. J. Aiton. Leibniz: Una Biografia, Alianza. Edt. Madrid, 1992.

${ }^{3}$ Cfr. Leibniz: Le meilleur des mondes par la balance de l'Europe. PUF. Paris, 1994. Y Correspondance Leibniz Castel de Saint Pierre. Centre de philosophie du droit- (Paris II-CNRS-URA.956) 2004.
} 
tinte cultural, pero otras tienen un indudable matiz político. En este capítulo entra su clara opción antiborbónica (Francia-España, recordemos que Luis XIV aún reina, pues muere en Septiembre 1715) y a favor del Imperio y de la casa de Brunswick enlazada además matrimonialmente con el Emperador y que Leibniz concibe como primera línea del Imperio dentro (y ahora quizá con Inglaterra) de los Estados Alemanes. No es imposible, parece pensar Leibniz, alcanzar una concordia de los «cristianos» de Europa dentro de un modelo imperial que dé cobijo a todas las confesiones. "Me ha alegrado mucho ver en la ceremonia de coronación que el Rey ha comulgado a la Inglesa. Me imagino también que Su Majestad continuará y que esta no sea solamente una conformidad ocasional» (K.XI.20) le dice a Carolina en su primera carta a Londres como Princesa de Gales.

Quizá podemos conjeturar que desde Viena (dadas sus buenas relaciones con miembros de la familia imperial) Leibniz concibe la Europa en equilibrio mediante la construcción de un entramado de relaciones familiares y políticas que comprenda desde Rusia a Inglaterra con el Imperio como centro. En ese entramado la casa de Brunswick — como decíamos - estaría llamada a jugar un papel principal con la aportación de su rama inglesa. Pudiera incluso pensarse que Leibniz se consideraba a sí mismo el promotor en Viena de lo que él pensaba que debería ser la buena política de su Patrono. Su nuevo cargo de Consejero Imperial desde 1712 pudo animarle a sentirse capaz de diseñar desde el centro del Imperio una "Europa cristiana» y en paz, organizada en torno al Emperador y con el apoyo que le daban los lazos familiares con la familia Brunswickiana. La correspondencia con Castel de Saint Pierre (Robinet, 2004) se mueve en este contexto. En la carta a Rèmond del 11 de Febrero de 1715 con la que remite (vía Varignon) la respuesta a Castel le dice que "Es cierto que si los hombres quisieran podrían librarse de los tres grandes azotes, la guerra, la peste y el hambre. En cuanto a los dos últimos, cada soberano lo puede hacer; pero contra la guerra sería necesario un acuerdo entre Soberanos que es difícil de obtener» (Gerhardt. P. III, 637).

Podemos preguntarnos ahora si hay alguna forma de comprender la larga estancia en Viena contra el disgusto de su Patrono. Matthew Stewart ${ }^{4}$, p.e., parece inclinarse por una de carácter egoísta — arribista diríamos también— pues le

${ }^{4}$ Cfr. M. Stewart: El Hereje y el Cortesano. Spinoza,Leibniz,y el destino de Dios en el. mundo contemporáneo. Ediciones de Intervención Cultural/Biblioteca Buridán, Barcelona, 2007. Cap. 17. 
presenta como un cortesano vividor en busca de patronos más generosos y menos displicentes que Jorge Luís. Traza una imagen de Leibniz como si en esta última etapa de su vida hubiese actuado como un cortesano mercenario que busca plaza en Viena, en París o en Londres como si ya supiera de antemano que su destino iba a ser la soledad y ostracismo de Hannover, condenado a no moverse de allí y a escribir la historia de la casa de Brunswick para complacer a su Patrono. $\mathrm{Y}$, aunque es posible que, una vez muerta Sofía, presintiese que las cosas no iban a ser igual, algo más que la pura necesidad debió hacerle salir de Viena a principios de Septiembre de 1714. Y ese algo bien pudiera estar relacionado con el nuevo papel que se imaginó como Consejero de la «Europa cristiana» en una extensión universalista de su «ireneísmo" político-religioso. Y quizá creyó que el nuevo (desde Agosto) Rey de la casa de Hannover era una pieza demasiado importante en el juego en que estaba pensando. Por ello debió parecerle necesario cambiar «provisionalmente» Viena por Hannover.

La correspondencia con Carolina se inicia muy tempranamente, hacia 1704, cuando la princesa de Ansbach estaba siendo «catequizada» en católico (K.IX.113), si bien es en estos años -1714-1716 cuando se hace frecuente y hasta muy importante. El 24 de Mayo de 1714 escribe desde Viena (K.IX.450) dando impresiones y consejos sobre la proyectada ida a Inglaterra del príncipe Heredero y esposo de Carolina. La oposición de los Tories (Bolingbroke) se materializa en cartas displicentes ("que son de una violencia digna de Mylord Bolingbroke» dice Carolina (K.IX.3-452) de la Reina Ana, que causan gran pesar en la corte de Hannover y tal vez la muerte de la Electora Sofía, — según cuenta la Condesa de Buckebourg (K.IX.3-457-62) -).Carolina se muestra muy apenada por las cartas recibidas de la Reina Ana y añade que «No me pesa tanto la pérdida que nuestra conducta nos pudiera acarrear, cuanto haber abandonado en cierta manera el interés de nuestra Religión, la libertad de Europa y a tantos valientes y honrados amigos en Inglaterra» (K.ibd. 452-53). El 16 de Junio Leibniz responde a Carolina (sin saber aún que la Electora Sofía ha muerto) dándole razones para no tener demasiada preocupación y mostrándole algunas de las posibilidades que aún cuentan, dado el buen ánimo que existe en Viena para con la casa de Hannover. Leibniz conoce la muerte de Sofía y los detalles de la misma por una carta de Schulenbourg del 13 de Junio (K.IX.3-481), pero aún tarda más de dos meses en regresar a Hannover. El 7 de Julio de 1714 escribe Leibniz su última carta a Carolina desde Viena. En ella encontramos la expresión más clara de la relación que existirá entre ambos los dos años siguientes hasta la muerte de Leibniz: 
«Señora: La muerte de Mdme. la Electora me ha producido una gran emoción. Me parece que la contemplo expirando en brazos de V.A.S. Esta muerte es la que ella deseó. No es ella, es Hannover, es Inglaterra, es el mundo, soy yo quienes la perdimos. La carta que V.A.S. me hizo la gracia de escribir la víspera de la muerte de Mdme. la Electora, me ha servido de gran consuelo. Ahora si Vos no queréis, Señora, recibirme como un viejo mueble que vos habéis heredado de ella, me desterraréis de Hannover. Será preciso que V.A.S. se haga donar sus colecciones. Gargan tiene mucho y después Mlle. Pellniz, además de lo que hay en su gabinete. Sería necesario suplicar a Mdme. d'Orleans que nos conservase sus cartas. Todas estas reliquias no son nada al lado de su persona. Pero no pensemos demasiado en su muerte sino más bien en su vida feliz y gloriosa. V.A.S. debe ser como su metempsicosis» (K.IX.462-63).

A partir de la llegada de Leibniz a Hannover su relación con la ahora ya Princesa de Gales se hace muy similar a la que había mantenido con la Electora Sofía y la primera carta que le dirige el día 3 de Octubre antes de partir la Princesa (el día 12) para Inglaterra (K.XI.15-17) es para contarle con detalle cómo él por su cuenta (de mon prope mouvement) le sugirió a la Duquesa de Zelle que hablara con el Rey Guillermo de Inglaterra de la conveniencia de designar a la Electora de Hannover para la sucesión del Trono inglés. Esta carta debió de tener un gran valor para Carolina, pues mostraba con claridad hasta dónde el destino de la familia había sido sutilmente guiado por aquél consejero, ahora desolado y casi abandonado por todos.

Leibniz, tras la marcha de Carolina a Londres, se siente desolado y (como él dice) se le hace Hannover «insoportable». Los ataques de gota son cada vez más intensos y frecuentes, lo cual nos indicaría que su optimismo no bastaba para atajar cierta sombra de depresión motivada, entre otras cosas, por el ostracismo físico y político en que se halla confinado. Además de las dificultades que se encuentra en Hannover, las cosas no van bien en la Academia de Berlín, tiene abierta la batalla del cálculo con los newtonianos, el proyecto de Viena se paraliza en su ausencia que además se hace forzosa y, al parecer, prolongada y Leibniz se vuelve hacia Carolina. En la misma carta en la que confiesa lo «insoportable» que le resulta Hannover y que, aunque sin fecha, podría ser de Noviembre-Diciembre de 1714 le dice: «...yo estoy aqui encerrado en mi habitación para trabajar sin salir apenas y sin preocuparme por otras noticias que las relativas a V.A.R. y a todo lo que le es querido. Es verdad que algunas veces recibo noti- 
cias de Viena: Mlle. De Klenk me transmite la continuación de la alegría que la Emperatriz Amalia tiene por la felicidad de la Casa Real y el Conde de Bonneval me dice que el Principe Eugenio pregunta por qué, no habiendo ido a Inglaterra, yo no regreso a Viena, donde se supone que yo no estaría mal. Pero yo quiero emplear este invierno en llevar mi trabajo hasta un estado que tras ello yo podría incluso tomar licencia para irme al otro mundo, sin que nuestra corte tuviese motivo para quejarse de mí. Si yo pudiera sobrevivir a esto un poco, veré cuanto se alabará mi celo. Me consuela que al menos V.A.R. y Mi Señor el Príncipe de Gales no lo menospreciarán". (K.ibd. 19-20).

En estas condiciones se produce la correspondencia final entre Leibniz y Carolina. Por desgracia no la conservamos entera pues el dossier en poder de Carolina no sabemos ${ }^{5}$ dónde está (si lo hubo) y por su parte Leibniz no debió hacer copia (o no la guardó o se ha perdido) de todas las cartas que escribió. La correspondencia cruzada desde 1704 hasta de Octubre de 1714 asciende a poco más de una docena de documentos conservados. De 1715 conservamos más de otros tantos y la noticia de algunos no conservados. Durante 1716 el intercambio fue algo más numeroso y desde finales de 1715 hasta la muerte de Leibniz (el último año escaso de su vida) hay que incluir en esta correspondencia la controversia con Clarke a través de la propia Carolina.

\section{La correspondencia de 1715}

Durante la primera parte del año los temas de esta correspondencia parecen más bien personales por parte de Leibniz, si bien es cierto que, además de Carolina, cuenta con otros corresponsales (pertenecientes al grupo de los hannoverianos acompañantes del Rey) dentro de la corte inglesa a los que expone también sus peticiones o propuestas; el más directo es el ministro Bernstof, la condesa de Buckebourg y Mlle. Pölniz. Además de solicitar la protección y benevolencia de Carolina (tema casi permanente en toda la correspondencia) Leibniz pide ayuda para que le paguen en Hannover sus atrasos (se le adeudan los salarios de los dos años de estancia en Viena) y con ello que le hagan justicia por sus servicios. Pero es un asunto personal del Rey y este parece poco inclinado a atender la peti-

${ }^{5}$ Sólo conservamos alguna en J.M.Kemble: State papers and correpondence illustrative of Europa, fronthe revolution to the accesion of the House of Hanover. J. W. Parker, Londres, 1857. 
ción ya venga vía Carolina ya por medio de Bernstorf. La primera carta de Carolina (16 Enero 1715. K.XI.32) le dice con toda claridad lo que piensa el Rey: "Yo creo, Señor, que si os proponéis dedicaros completamente a la historia de la familia, podéis conseguir todo lo que deseáis». Lo que Leibniz deseaba era acompañar al Rey a Londres y formar parte de la corte inglesa, lo cual requería un empleo que Leibniz se imaginaba como "Historiógrafo del reino». En este momento en la mente de Leibniz había dos cosas importantes. La primera estaba relacionada con su disputa con Newton sobre el cálculo ${ }^{6}$ y la segunda con sus pretensiones de consejero sobre la dirección de la política europea.

Carolina escribe dos muy breves cartas hasta septiembre, mientras Leibniz escribe al menos cuatro en este tiempo, aunque si contamos las indirectas vía Berntorf y Mlle Pölniz pudieran ser el doble. De hecho la carta de Carolina de 13 de Septiembre 1715 (K.XI,46) comienza "La Condesa de Buckebourg me ha entregado vuestra carta. El hombre que habeis recomendado no ha aparecido ante mi». También pudiera ser que nos falten algunas no conservadas. Así por ejemplo Carolina comienza su carta de 14 de Noviembre 1715 (K.XI.49) diciendo "¿De dónde viene que creáis, Señor, que yo pueda olvidar a un hombre como vos?". Pero no conservamos ninguna carta de Leibniz en que aparezca esta queja, salvo que sea una expresión retórica empleada por Carolina.

Por parte de Leibniz la carta más representativa de sus pretensiones en 1715 es una del 10 de Mayo (K.XI.37-40). Explica que su petición de historiador del reino la ha formulado también a través de Bernstorf y que el motivo por el que ambiciona este cargo "est en bonne partie le point d'honneum. No quisiera, añade, ceder en nada a un cierto Antagonista que los ingleses me han enfrentado. La parte central de esta carta resume para Carolina los avatares de la disputa y adorna estos con dos argumentos. Uno que sus contrarios en esta disputa son, también contrarios a la causa de Hannover y antigermánicos, y, otro, que además son partidarios de una filosofía muy poco compatible con la religión que profesan los cristianos reformados. Le transmite la idea de que en materia filosófica Newton y los suyos tienen graves inconvenientes a los que hay que oponerse y en cuanto a la disputa del cálculo "personas competentes tanto de Francia como de

${ }^{6}$ Cfr. Antonio J. Durán: La polémica sobre la invención del cálculo infinitesimal- escritos y documentos. Ed. Crítica. Barcelona (2006). La muy amplia y excelente Introducción nos ahorra detenernos en este asunto y nos remitimos a ella. 
Suiza lo han hecho por mi». De un modo u otro Leibniz sabe ${ }^{7}$ que Carolina está en estos momentos leyendo a Locke porque termina su carta diciendo a Carolina "admiro que V.A R. parezca haber encontrado la debilidad de Locke» y dedica el resto a comentar las pocas relaciones que tuvo con él a través de Lady Masham.

No hay una carta de Carolina (que conservemos) hasta el 13 de Septiembre y en ésta responde a una enviada a la Condesa de Buckebourg y en ella le hace la famosa declaración del Rey: "He tenido la oportunidad de hablar al Rey en vuestro favor y me ha dado esta respuesta: "Er muss mir Erst wisen, das er historien schreiben kann; ich höre er ist fleissig"” (Primero tiene que demostrarme que puede escribir la historia; he oído que es diligente) (K.XI.46). Carolina interpreta esta palabras en el sentido más favorable pues añade que "no dudo de que cuando llegue el Rey al Electorado vuestro asunto llegue al término deseado". Es muy probable que Leibniz interpretase estas palabras del Rey de un modo muy diferente. Si su papel se reduce a la tarea de cronista e historiador de la casa de Brunswick, en la biblioteca ducal y, como mucho, en las bibliotecas de la familia, los proyectos surgidos en Viena tras sus dos años de gestiones en la corte Imperial, ya no podrán realizarse. Su posición de Consejero queda convertida en consejero de nadie, pues estará lejos de todos lo centros de decisión y la política de Europa seguirá su camino sin que sus opiniones sean escuchadas en parte alguna.

En la colección de Klopp la carta que sigue a esta de Carolina que acabo de comentar aparece una de Leibniz sin fecha y con una nota manuscrita de Leibniz (Nicht abgangen). Quizá fue redactada en un momento de gran enfado y luego, al serenarse, decidió no enviarla, ni tampoco otra en su lugar. O quizá ya había enviado una muy poco antes y, como dice al principio de esta, "después de haber escrito una larga carta a V.E.R., no debería volver a escribir tan pronto" (K.XI.47). No conservamos esta «larga carta» mencionada. Pero en esta (no enviada) Leibniz dice a Carolina que le han jugado una treta consistente en decirle al Rey que estaba a punto de marchar a Viena. El resultado fue una orden expresa del Consejo prohibiéndole los viajes («le conseil m’a ordonné d’une maniere rebu-

${ }^{7}$ Una muy breve carta de Mlle Pölniz (K.XI.37) que da motivo a Leibniz para escribir la que estamos comentando, contiene un recado de Carolina; le dice la Princesa que está leyendo a Locke, que encuentra cosas que Leibniz no suscribiría y que no le escribirá hasta que el Rey le conceda la petición que Leibniz le ha hecho. Si la promesa se cumple el silencio durará hasta el13 de Septiembre. 
tante ce que jaurois assez fair sans son ordonnance») $)^{8}$. Las reiteradas protestas de honestidad y lealtad que siguen a esta manifestación muestran hasta qué punto Leibniz se sintió maltratado y humillado y, en definitiva, fuera y apartado del circulo del Rey. Además aún siguen sin pagarle sus atrasos y espera que el Rey ordene pronto que lo hagan. En esta carta Leibniz termina haciendo unas consideraciones sobre el giro que toman los acontecimientos en Europa tras las muertes de la Reina Ana y del rey Luis XIV (por tanto hay que situarla hacia Octubre de 1715), consideraciones que le llevan a concluir lo inevitable que hubiera sido recurrir al Emperador, caso de que estas muertes no se hubieran producido (por tanto-para buenos entendedores- lo acertado y útil de sus contactos con la corte de Viena que tan mal sentaron al Elector). En definitiva la carta no fue enviada, quizá para no poner las cosas peor. A nosotros nos sirve para saber algo mejor cómo estaban.

Si ahora nos detenemos en una lectura atenta de las dos cartas siguientes de Carolina ambas de Noviembre 14 y 26 (K.XI.49-52) entre las cuales no media (que sepamos) ninguna de Leibniz resulta muy sorprendente el tono familiar y de pequeñas noticias domésticas que Carolina le hace llegar en la primera de ellas, como si Leibniz hubiese preguntado por algunos personajes de la vida cortesana. En esta primera, de pasada, le dice que «Hoy mismo he hablado con el Obispo de Lincoln sobre la traducción de vuestra Teodicea. No hay nadie capaz de esto, según me asegura, más que el Dr. Clarke, cuyos libros os he mandado por Oienhausen: Este mismo hombre es amigo intimo del Caballero Newton y no creo la cosa en muy buenas manos». Todo lo demás son pequeñas noticias de lecturas (la traducción de Homero debida a Pope) Addison, Fallaiseau, bromas con un soneto etc.

Pero el tono cambia en la segunda. Para empezar «todo lo que habéis dicho sobre lo que se os debe de vuestros sueldos de Hannover es tan justo y está tan bien expuesto que hubiera creido estropear la cosa si no le hubiera dado a leer al Rey vuestra carta, que pareció contento y me dijo que era muy viva y estaba muy bien escrita. No dudo de que vuestro asunto ya estará resuelto para la llegada del Rey». Dando por resuelto este asunto salarial, Carolina lleva su preocupación a algo que ha debido discutir con o leer en las obras de Clarke, pues pasa directamente a afirmar que ella "no es nada jesuita. Pero hay que hacerles justicia....en lo que creen de la gracia que es más razonable y

${ }^{8}$ Aiton (l.c). dice que esta orden se produjo a primeros de 1715. Si tomamos en cuenta esta carta parece que más bien fue hacia el otoño. 
conviene más a Dios». Le pide a Leibniz que le haga llegar su opinión sobre las obras de Clarke que, aunque no le parecen mal, no cuadran bien con la Teodicea. Y tras una alabanza y declaración de afecto y agradecimiento al amigo, pasa de nuevo a su disputa con Clarke. Primero porque quiere traducir la Teodicea. «Nous pensons fort serieusement à faire traduire votre Teodicée, mais nous cherchons un bon translateur». Entre los posibles el más capacitado es Clarke, pero «il est trop opposé a vos opinions». Y, por si esto fuera poco, "Il est trop de l'opinion de Sir Isaac Newton, et je suis moymême en dispute avec luy. J'implore votre secours». Esta confesión y esta petición de ayuda pueden ser el origen inmediato de la controversia mantenida durante el año siguiente: el extracto de una carta de Leibniz que constituye el primer documento de esta controversia. Las líneas que siguen inmediatamente en esta carta representan el problema al que responde casi literalmente el «extracto» que abre la controversia: «El [Clarke] dora la pildora, y no quiere reconocer en modo alguno que M. Newton tenga las opiniones que vos le estáis atribuyendo. Pero en efecto, vos veréis por los papeles adjuntos que es la misma cosa. Yo no puedo jamás creer otra cosa que lo que conviene a la perfección de Dios. Y la encuentro mucho más perfecta en vuestras opiniones que en las de Mr. Newton... El Dr. Clarke ni Newton quieren declararse de la secta de Locke, pero yo ni puedo ni quiero ser da la suya. Ellos tienen otra opinión del alma...». Siendo esta carta de 26 de Noviembre de 1715 resulta muy apretado que Leibniz la recibiera y respondiera con una carta o el «extracto» dentro del mes de Noviembre. Sin embargo, aunque resulte apretado, así debió de ser, pues el año 1715 se cierra con, al menos los dos primeros escritos de la controversia.

\section{El último año. 1716}

No tenemos fecha segura para el primer documento de la controversia, pero tampoco para el segundo (primero de Clarke) ni para la primera carta de Leibniz (K.XI.58) que debiera corresponder a los penúltimos días de 1715 En esta carta, además de las felicitaciones para el nuevo año y de algunas consideraciones sobre la posición del Rey en materia religiosa entre reformados y anglicanos menciona el escrito de Clarke (el primero) y hace a la Princesa consideraciones sobre las debilidades argumentales de Clarke sobre el alma. Habla de la presencia en Londres del Abate Conti e indica que, aunque cuando estaba en París se mostraba muy adicto a las propuestas de Leibniz, pero ahora «no se si mis Señores Antagonistas de Londres no le habrán seducido». Pero se muestra generoso y añade "Me gustaría que él tuviese el honor de ser conocido de V.A.R.». Finalmente 
comunica a la Princesa que su valimiento ante el Rey ha tenido éxito aparentemente y le pagarán en breve sus atrasos.

El dia 30 de Diciembre de 1715 (K.XI.71 y Kemble.534) Carolina escribe a Leibniz enviándole «une reponse à votre papier... Je ne sais si la prèvention que jai por votre mèrite me rend partiale, mais je trouve toute réplique, plutot des mots, sans que se les puisse nommer des réponses». Tanto la carta de Carolina como el segundo escrito de Clarke debieron llegar a poder de Leibniz en Enero de 1716.

Tomando estas fechas como seguras, el resto de la correspondencia en la disputa con Clarke pertenece a 1716 y representa una buena parte de las posturas finales de Leibniz en relación con la filosofía de sus "Antagonistas» Londinenses. La controversia, como es bien sabido tiene dos asuntos: uno con motivo de las acusaciones de Keill-Newton relativas a invención o plagio del cálculo infinitesimal. En este frente Leibniz viene actuando ya desde hace un tiempo tanto en correspondencia con J. Bernouilli como con Wolf pero ahora, además, acude a la cita Londinense mediante sus cartas con Conti-Newton ${ }^{10}$ durante los meses de Febrero-Marzo. Desde Octubre anterior (vía Remond —GP. III 651 y stss—) tenía muy buena información de las andanzas y mudanzas newtonianas de Conti y se daba cuenta de que sus protestas de honestidad no bastaban para imponer la verdad ante los partidarios del gran "Antagonista». Esto hace que, con el viento a favor de Carolina interesada en traducir la Teodicea sin encontrar traductor idóneo, Leibniz formule sus reproches hacia la filosofía inglesa en el Extracto que se tomó como punto de partida. Se suele fechar en Noviembre de 1715 y bien pudiera haber acompañado a una carta enviada en el lugar de la que conservamos como "No enviada». En cualquier caso parece un pequeño resumen para Carolina escrito con el fin de orientarla sobre el terreno que pisaba tanto en sus lecturas como en su disputa con Clarke y los newtonianos. La aparición de Conti (quien confiesa a Rèmond que visitaba tres veces por semana a Newton (GP.III.655) tras la presentación que de él hiciera Leibniz a Carolina da lugar a la intervención de la Princesa en la disputa del cálculo ${ }^{11}$, intervención que durante este año 1716 se solapa con la controversia teológico-filosófica que ahora se va abrir. Si tenemos en

9 Robinet (en su Edición de la Correspondencia Leibniz-Clarke) toma esta carta de Kemble con fechas 20/30 de Diciembre. Klopp la fecha en St. James 30 de Diciembre 1715/10 de Enero/1716.

${ }^{10}$ Cfr. Antonio J. Duran: págs. 139 y stss.

${ }^{11}$ Cfr. A. J. Durán: l.c. 141. 
cuenta que esta correspondencia entre Leibniz y Carolina coincide con otras muy importantes dirigidas a Viena, a Berlín a París a Wolf, a Bernuilli, a Desmaizeaux, a los hermanos Rèmond, etc. así como con la historia de la casa Brunswick además de la Historiola (A. J. Duran. 231 y stss) y Los Principos Metafísicos de la Matemática (E. Olaso. 581 y stss.) podemos entender muy bien y en su sentido más literal la frase de M. Stewart: "Leibniz pasó el año que hacía setenta y el último de su vida no menos prodigiosamente que todos los anteriores» (M. Stewart. 293).

La correspondencia Newton-Conti- Leibniz tiene lugar durante el mes de Marzo (26 Febrero-29 marzo 1716 NC. VI-285 y stss) ${ }^{12}$ y ciertas secuelas como la siguiente carta a Conti y otra a la Baronesa de Kilmansegge (ibd. 322 y 324) todas relacionadas con la disputa del cálculo nos hacen pensar que Leibniz dedicó mucho esfuerzo a esta cuestión hasta que se convenció de que no serían los poderes de la corte, sino los de la historia, quien decidiese. Por ello podemos explicar que Leibniz y Carolina sólo se crucen dos cartas cada uno en cuatro meses. Leibniz el 25 de Febrero (K.XI.78) envía su tercer escrito a Clarke y responde favorablemente a la propuesta conciliatoria de Carolina-Conti (carta de Carolina de 10 de Enero) si bien pide «que la Real Sociedad le haga justicia y que declare que no ha querido poner en duda su honestidad, ni permitirá hacerlo». La siguiente carta de Leibniz ( sin fecha) (K.XI.85) va dedicada a reabrir la cuestión de la unidad de las confesiones protestantes aprovechando la coyuntura histórica de que un luterano es el jefe de la Iglesia Anglicana y la unidad sería muy fácil si los luteranos de Prusia se aviniesen con los de Brunswick. Por su parte, Carolina, además de la que acabamos de mencionar, escribe el 24 de Abril (K.XI.90) en términos que debieron desengañar a Leibniz más de lo que dio a entender. Resumiré mucho la carta de Carolina 1) Ha recibido todas sus cartas. 2) Los obispos no se ponen de acuerdo en el asunto de la reunificación y el Arzobispo exige que los Obispos anglicanos pasen al continente y procedan a ordenar «in sacris» a los luteranos. 3) Reprocha a Leibniz que crea que ella ha cambiado de opinión (respecto a la filosofía de Leibniz). 4) Lo que Clarke ha editado son cartas antiguas con un clérigo escocés.5) Conti le ha perdido los papeles y por eso no puede enviar con esta la respuesta de Clarke. 6) El sábado anterior estuvieron Conti y Clarke discutiendo con ella de 6 a 10 y le echó de menos pues Clarke casi la convirtió a la teoría del vacío. 7) Ha visto la carta que Newton le ha enviado vía Conti. Espera la respuesta

${ }^{12}$ Cfr. The Correspondence of Isaac Newton. NC. VI. Cambridge U.Press. N.C en los suesivo. 
de Leibniz. Desespera de verlos reconciliados, «los grandes hombres son como las mujeres que jamás ceden a sus amantes más que con la última amargura y cólera mortal».8) Ha mostrado una carta al rey en la que habla del enviado de Módena (?) Y acaba diciendo que era mejor que tratasen de hacer al mundo más justo mediante sus matemáticas «au lieu de vous queeller, je dis l'un et l'autre».

El 15 de Mayo Carolina vuelve a escribir. Empieza con noticias a) Envía la carta de Clarke que ha sido encontrada. b) Conti y su muy lista alumna me han perdido algunos de vuestros papeles; agradece que se los reponga. c) El Rey le ha mostrado la carta que Leibniz había escrito a Mlle Pölniz. d) Ha visto la respuesta de Leibniz a Conti. El resto es una reprimenda por la disputa, reprimenda que termina diciendo «laissez tomber vos disputes sèrieuses, et prouvez-nous le plein, et que le chevalier et Clarke de leur côté preuvent le vuide». Pero las últimas líneas de esta carta debieron dejar perplejo (si no lo estaba ya) a Leibniz. Carolina añade: "Mañana veremos los experimentos de los colores y uno que yo he visto en favor del vacio, casi me ha convertido. Vuestra tarea, Señor, es hacerme volver al buen camino, y espero la respuesta que daréis a Clarke».

Leibniz escribe el 12 de Mayo y aún no debe tener en sus manos la última carta de Carolina (fechada el 4/15 de Mayo). Sin embargo, tras pedir perdón por sus anteriores reticiencias, que atribuye a la manera de actuar de Conti. No le parece leal su conducta y no duda en calificarla de "camaleónica» término que podemos traducir en el contexto por «sin principios» pero también «servil». Y pasa a comentarle la carta que ha remitido para Newton en la que dice que los fundamentos «en cuestiones de hecho» que Corolina había encontrado en la carta de Newton, ahora quedaban convertidos en "hechos imaginarios», mientras lo que se puede "alegar contra él, no es más que demasiado real». Tras darle las razones de esta situación Leibniz se lamenta de que le hayan obligado a llegar a ella (Newton incluido) y no tiene ningún inconveniente en ir a la reconciliación siempre que reconozcan el mal camino emprendido y le dejen en paz.

Todavía Leibniz insiste aquí en su esperanza de encaminar a los protestantes hacia la unión porque es la ocasión más propicia jamás tenida y cita «muchos profetas y Reyes quisieron ver lo que vosotros veis y no pudieron verlo". Adjunta como P.S. un texto con los argumentos contra el vacío, porque también en esto comprende que está perdiendo la batalla ante la «juez» Carolina. 
La respuesta es del 26 de Mayo. Carolina le dice que hace bien en pedir perdón por haber tenido la osadía de suponer en ella «quelque refroidissement». Defiende la buena voluntad de Conti y la honestidad intelectual de Newton y le ruega, una vez más, que se deje de disputas y procure emplear su tiempo más útilmente. Pero añade: "Estoy con los experimentos, y cada vez más encantada con los colores. No puedo evitar estar un poco prevenida respecto al vacio; pero creo que no se comprende, pues lo que estos Señores aqui llaman asi no debe significar nada, sino una cosa que no es materia».

Esto, para Leibniz sólo podía ser una señal más de que Carolina estaba siendo «convertida» o, al menos, inclinada hacia la filosofía rival y de que su magisterio con Carolina estaba siendo suplantado con cierto éxito como consecuencia, principalmente, de su alejamiento forzoso. Otra mala noticia para Leibniz era que el Rey, aunque aprobaría la unión de las Iglesias protestantes, difícilmente haría nada por sacar a los obispos de su idea de «consagrar» a los hermanos luteranos. Es muy probable que Leibniz a estas alturas se viese como perdedor en toda la línea inglesa. La carta siguiente (K.XI.114) de Carolina - 15/26 de Junio- parece respuesta a una no conservada de Leibniz, pues comienza «No he podido responder antes, Señor, a vuestra carta del 2 de este mes... Me permitiréis, pese a que he encontrado un poco de acritud en vuestra carta hacia mi, que esté disgustada por ver a dos personas de vuestro mérito despellejarse por la vanidad que deberíais destruir por la bondad de vuestros razonamientos. ¿Qué importa que voso el caballero Newton haya descubierto el cálculo?». Estas palabras dejarían a Leibniz pensativo, pues, pese a haberse quejado de que lo que rechaza es la acusación de plagio que los ingleses le hacen, se le reprocha a él por defenderse más que a los rivales por su injusto ataque. Una y otra vez se queja de la injusticia y ésta no parece preocupar $¡$ ni siquiera a Carolina!

El resto de la carta parecería, por su tono más consoladora. Pero tampoco. La Teodicea no parece que guste del todo al Arzobispo y es extremadamente difícil encontrar traductor. Las menciones de Clarke, Conti parecen impregnadas de benevolencia hacia ellos sobre todo «le pauvre Abbé qui croit etre médiateur» ${ }^{13}$.

${ }^{13}$ La doblez de Conti, su servil entrega a la gloria de Newton queda más patente si consideramos lo que dice en la última carta que escribió a Newton desde Hannover el 20 de Noviembre de 1716, cuando aún el cuerpo Leibniz no había recibido sepultura (Cfr. NC. VI, 376) Si comienza diciendo «M.Leibniz est mort; la dispute est finie» y continúa "comme je sperre que le Roy me donnera 
Ciertamente se despide con afecto. El Rey ya está en Hannover y es probable que tuviese dudas respecto a las relaciones que establecería Jorge Luis con su historiador.

El 31 de Julio (K.XI.128) Leibniz escribe a Carolina explicándole que su respuesta al cuarto escrito de Clarke se aplazará un poco por diversas razones. Pero aprovecha para dejar claro que no hay en él «animosité et passion contre M. Newton». Añade para que quede claro: «Si V.A.R. hubiese visto con qué grosería sus adeptos me han atacado, cosa que él no ignoraba en absoluto, Ella hubiese alabado mi moderación. Yo no me he dignado responder a tales gentes que no tienen ninguna (dignidad). Pero cuando Mr Newton ha querido aparecer por si mismo, yo le he respondido como es preciso, y espero que mi respuesta haya dejado satisfechos a quienes la hayan querido examinar, y esto no solo por el lado de la justicia de mi causa, sino también respecto a las maneras. Yo no podia soportar expresiones que atacaban mi buena fe, y era necesario responder con contundencia; pero creo que se notará bastante que lo he hecho sin emoción».

Tampoco se queja de Conti. Al fin y al cabo sólo "había notado que habia dejado de ser neutral", y eso no es cosa para que se quejase. La Teodicea no tiene más abogado en Inglaterra que Carolina y si Ella desea que se traduzca se podrá lograr. Por su parte Leibniz le hace llegar vía Des Maizeaux- Zollman los manuscritos que le faltan.

El 18 de Agosto (K.XI.131) escribe de nuevo. No parecen ir mal sus relaciones con el Rey, y pasa a los asuntos que nos importan:

«Mi respuesta al cuarto escrito de Clarke va aquí en parte. La otra mitad llegará con el correo siguiente. Esta respuesta es muy amplia puesto que yo he querido explicar las cosas a fondo, y ver por ello si hay esperanzas de hacer entrar en razón a Mr. Clarke. Porque si se dedica a las repeticiones, nada habrá que hacer con él, y será necesario terminar honestamente».

\footnotetext{
la permissión de voir les papiers, je remarquerai sill y a quelque chose touchant votre dispute, mais peutetre qu'on cachera ce qui ne fait point d'honeur a la memoire de M. Leibniz», concluye asi: «Si il y aura quelque chose de nouveau touchant l'affaire de M. Leibniz je vous informerai avec toute l'exactitude. Il n'y a peut-etre une persone plus interessé por votre gloire, que moy». Con esto desapereció Conti de mundo y se acabó su mediación. El juicio de F. Manuel no parece exagerado (cf. A. J. Durán. o.c. 140).
} 
Leibniz sigue interesado en propiciar la traducción de la Teodicea y expone algunas nuevas noticias sobre posible traductor vía Des Maizeaux. Vuelve sobre ello en carta de 11 de Septiembre (K.XI.182) en la que repite que si Clarke sigue sin concederle el "gran principio de razón suficiente... será necesario abandonarlo a su sentido, o más bien obstinación».

Por parte de Leibniz esta correspondencia (K.XI.186) se cierra con una carta sin fecha, tal vez de la primera mitad de octubre. Es larga y está llena de detalles sobre lo que ocurre en la corte del Rey Jorge y, aparentemente de buen humor. Se burla de Conti (Carolina le había dado cuenta de sus hazañas amorosas con la embajadora de Venecia). "Los sermones de Conti podrian dar asunto a una novela filosófica..... Yo no creía que en Italia estuviera permitido cortejar a las damas en tales circunstancias. Si el Embajador no se enfada en absoluto, es preciso que crea que los filósofos no son peligrosos. Si, sin duda, si son de mi edad».

Esta carta, y nosotros con ella, acaba con dos despedidas. Una diciendo adiós a Clarke. "Si no me concede este gran axioma recibido que nada ocurre sin que haya una razón suficiente de por qué ocurre más bien asi que de otra manera, yo no me podré culpar de dudar de su sinceridad, y si lo concede, adiós a la filosofía de $\mathrm{Mr}$. Newton». La segunda diciendo adiós a Carolina: «Asi yo no espero ir pronto a Inglaterra. Nada me podría dar mayor deseo de ir alli que las bondades de V.A.R.; pero como yo no lo espero en absoluto para pronto, yo no se si lo puedo esperar para después, porque no hay gran después que esperar para mi».

Recibido: 4/02/2009

Aceptado: 20/02/2009 